\title{
Safety, feasibility, and efficacy of associating liver partition and portal vein ligation for staged hepatectomy in treating hepatocellular carcinoma: a systematic review
}

\author{
Junwei Zhang, Hanchun Huang, Jin Bian, Xinting Sang, Yiyao Xu, Xin Lu, Haitao Zhao \\ Department of Liver Surgery, Peking Union Medical College (PUMC) Hospital, Chinese Academy of Medical Sciences and Peking Union Medical \\ College, Beijing, China \\ Contributions: (I) Conception and design: J Zhang; (II) Administrative support: X Sang; (III) Provision of study materials or patients: Y Xu, X Lu, H \\ Zhao; (IV) Collection and assembly of data: J Bian, H Huang; (V) Data analysis and interpretation: J Zhang; (VI) Manuscript writing: All authors; (VII) \\ Final approval of manuscript: All authors. \\ Correspondence to: Yiyao Xu, PhD; Xin Lu, PhD; Haitao Zhao, PhD. Department of Liver Surgery, Peking Union Medical College (PUMC) Hospital, \\ Chinese Academy of Medical Sciences and Peking Union Medical College, Beijing, China. Email: xuyiyao@hotmail.com; luxinln@163.com; \\ pumchzht@aliyun.com.
}

\begin{abstract}
Associating liver partition and portal vein ligation for staged hepatectomy (ALPPS) allows radical resection of colorectal liver metastasis (CRLM). However, the effect of ALPPS on hepatocellular carcinoma (HCC) is not completely understood. This systematic review aimed to examine the existing data on the safety, feasibility, and oncologic effect of ALPPS on HCC. Electronic databases, including PubMed, Web of Science, and Embase, were systemically searched to identify articles on ALPPS and HCC. Additional articles were identified manually. The feasibility (liver hypertrophy between two stages), safety (90-day mortality), and therapeutic effect (long-term survival) were analyzed. Nine published articles that satisfied the retrieval standards were included, and these studies involved 176 patients. The evidence level of the enrolled studies was low, among which, the greatest Oxford evidence level was 2c. Additionally, the average median increase in future liver volume was $178 \mathrm{~mL}$, the average interval between two stages was 11.2 days, the interval was remarkably longer in radiofrequency-assisted ALPPS (RALPPS) patients (28 days), and the average 90-day mortality was $17.6 \%$ (range, 0-50\%). However, the oncological outcomes were not well documented. Survival following ALPPS was evidently improved compared with that after transcatheter arterial chemoembolization (TACE). This value was comparable to that following the one-stage hepatectomy and portal vein embolization (PVE), and it was similar to that in CRLM patients over the long term. Publication biases caused by case series and single-center reports are common in the review. It is concluded in this review that ALPPS is a safe and feasible approach to treat selected patients with unresectable HCC, but its oncological outcome requires further study. RALPPS is not recommended for HCC patients because of the long waiting time between the two stages.
\end{abstract}

Keywords: Safety; feasibility; efficacy; associating liver partition and portal vein ligation for staged hepatectomy (ALPPS); hepatocellular carcinoma (HCC)

Submitted Mar 05, 2020. Accepted for publication Aug 21, 2020.

doi: $10.21037 / \mathrm{atm}-20-2214$

View this article at: http://dx.doi.org/10.21037/atm-20-2214

(C) Annals of Translational Medicine. All rights reserved. 


\section{Introduction}

Liver cancer has the sixth highest morbidity rate, and it is the fourth leading cause of cancer-related death in the world (1). Hepatocellular carcinoma (HCC), which comprises $75-85 \%$ of liver cancers, is one of the most common malignancies in China, and it is often related to hepatitis B and cirrhosis. HCC patients are mainly treated by surgical resection, which is the only chance for curative treatment (2). However, many patients are diagnosed at an advanced stage, and are deprived of the chance for surgical treatment because of a small future liver remnant (FLR) (3).

Associating liver partition and portal vein ligation for staged hepatectomy (ALPPS), which was first introduced in 2012 by Schnitzbauer et al., has been widely adopted and applied in a large number of clinical situations with numerous variations $(4,5)$. On the basis of the results of meta-analyses and clinical trials, ALPPS can improve resectability and achieve great FLR hypertrophy compared with those of conventional two-stage hepatectomy, such as portal vein embolization (PVE) and portal vein ligation (PVL), for patients with advanced colorectal liver metastasis (CRLM) $(6,7)$. However, only a single-center experience has been reported when it comes to unresectable HCC with hepatitis B virus (HBV) infection (8-12).

Consistent results have not been obtained in these studies. For example, some studies have shown that it is feasible and safe to apply ALPPS in HCC patients, which can result in an FLR hypertrophy that is equivalent to that in non-HCC patients $(8,9)$. However, other studies have demonstrated the high morbidity and mortality for HCC (10-12), and controversy remains about ALPPS. For example, the extent of cirrhotic involvement cannot be accurately determined before surgery, which may lead to different indications under various institutions, and the different time intervals between the first and second stages. Moreover, many critics argue that ALPPS presents an unreasonable risk because of its high morbidity and mortality rates (13). Therefore, it remains controversial whether such a high price should be paid in exchange for the greater liver hypertrophy.

The aim of this work was to assess the safety, feasibility, and efficacy of ALPPS for HCC cases through a systematic review. We present the following article in accordance with the PRISMA reporting checklist (available at http://dx.doi. org/10.21037/atm-20-2214).

\section{Methods}

\section{Data sources and retrieval strategy}

Three data sets, including the Web of Science, Embase, and Medline, were systemically retrieved using the following retrieval strategy [(associating liver partition and portal vein ligation for staged hepatectomy OR in situ split OR ALPPS) AND (carcinoma hepatocellular OR carcinomas hepatocellular OR hepatocellular carcinomas OR liver cell carcinoma adult OR liver cancer adult OR adult liver cancer OR adult liver cancers OR cancer adult liver OR cancers adult liver OR liver cancers adult OR liver cell carcinoma OR carcinoma liver cell OR carcinomas liver cell OR cell carcinoma liver OR cell carcinomas liver OR liver cell carcinomas OR hepatocellular carcinoma OR hepatoma OR hepatomas)], to identify the related human studies. The last electronic search was performed on December 30, 2019. To avoid omitting any relevant study, the reference lists in all included studies were reviewed, along with several recent review articles that seemed to fulfill our requirements. Additional information was obtained from the authors upon reasonable request.

\section{Study selection and inclusion criteria}

Studies were identified in accordance with standard procedure that is described below. First, duplicate studies were excluded. Second, titles were screened, and only articles that were relevant to HCC and ALPPS were selected. In addition, abstracts and full-texts were reviewed if it was not possible to exclude the studies by titles alone.

The inclusion criteria were as follows: (I) studies investigating ALPPS and HCC; (II) human studies; (III) studies with available relevant data; and (IV) studies published in English. The exclusion criteria were as follows: letters, editorials, and case reports (study that reported $\leq 3$ patients).

\section{Data extraction}

Baseline characteristics of cases that received ALPPS were collected from the enrolled studies. Typically, information 
on age, surgical approach, tumor type, interval between two stages, preoperative volumetry, and kinetic growth (mL/day), was analyzed in all the included studies. The indications for ALPPS that were suggested in each of the enrolled studies were assessed. Typically, ALPPS was reported in liver cancers with FLRs that were too small for one-stage surgery ("marginally resectable"), and it was also reported to be the salvage strategy following certain previous portal vein manipulations that did not lead to sufficient growth for resection ("salvage"), such as PVE. We also collected the surgical methods and main topics from each study.

Data about feasibility, safety, and efficacy were collected in accordance with previous methodology by Schadde (14). Remnant liver hypertrophy between the two stages and microscopic tumor clearance in the stage 2 procedure were related to feasibility. Death or $\geq$ grade IIIa complications were associated with safety. Complete resection (R0) or incomplete resection (R1), overall survival (OS), as well as disease-free survival (DFS) were related to efficacy.

\section{Quality assessment}

Manuscripts were divided on the basis of the evidence level in accordance with the definition by the Evidence-Based Medical Center at Oxford (http://www.cebm.net/ index. aspx?o=1025). Because of the small number of studies, most of which were single-center experiences, we included all the studies for quantitative analysis if they reported relevant data.

\section{Results}

\section{Included studies}

The flow diagram for literature retrieval is displayed in Figure 1. Overall, 571 articles were primarily retrieved from the above-mentioned databases, and 341 articles were retrieved from the references. First, 334 duplicates were initially eliminated. After screening the titles of 578 studies, those regarding ALPPS for other tumors and animal experiments were excluded. Fifty-nine studies that satisfied the inclusion criteria were identified, and the full text of each of these studies was reviewed. Finally, nine eligible articles were included in this systematic review.

\section{Classification into evidence-level groups}

Four out of the nine included studies were case-series, with an evidence level of $4(11,12,15,16)$. There were four comparative studies involving 108 HCC patients who underwent ALPPS. Two studies enrolling 91 HCC patients who were treated using ALPPS and the control group were classified as having an evidence level of 3 a because of their individual study nature, in which the confounding factors were adjusted through multivariate analysis $(8,9)$. Two studies comparing HCC patients with non-HCC patients who were treated by ALPPS were assigned an evidence level of $3 \mathrm{~b}$ because they had small sample sizes $(17,18)$. The study analyzing the ALPPS registry of 260 cases was assigned as "outcome research", and it had an evidence level of 2c (10).

\section{Patient features}

There were 176 patients in the included studies, with an age range of 23 to 83 years and an average age of 56.4 years (Table 1). Additionally, 127 patients were from Asia. Indications for ALPPS were mentioned in 136 cases. FLR/standard liver volume (SLV) of $<30 \%$ in normal liver and $<40 \%$ in patients with cirrhosis were the most common indications for ALPPS. Two studies advocated FLR/SLV $<40 \%$ as an indication for HCC patients, regardless of the presence or absence of cirrhosis. The Metavir grade, which is a score that determines the degree of liver fibrosis via liver biopsy, was used in most studies to evaluate the degree of cirrhosis.

\section{Feasibility for ALPPS}

Seven out of nine studies reported FLR before stages 1 and 2, which occurred in 165 patients (Table 2). The average future liver volume before stage 1 was 357.4 (range, 151.1$655) \mathrm{mL}$, while that before stage 2 was 543.1 (range, 104$1,355) \mathrm{mL}$. The average median increase in volume was $185.7 \mathrm{~mL}$, the average interval was 11.2 days for standard ALPPS patients, and the average interval was remarkably longer for radiofrequency-assisted ALPPS (RALPPS) patients (28 days). The average rate of performing stage II surgery was $96 \%$ (range, $80-100 \%$ ).

\section{Safety for ALPPS}

Table 3 summarizes the primary safety endpoint of mortality at 90 days, which ranged from $0 \%$ to $50 \%$, and the average 90 -day mortality was $17.6 \%$. The most common reason for the mortality was post-hepatectomy liver failure. Sepsis, recurrence, and HCC metastasis are also causes of mortality (Figure 2). 

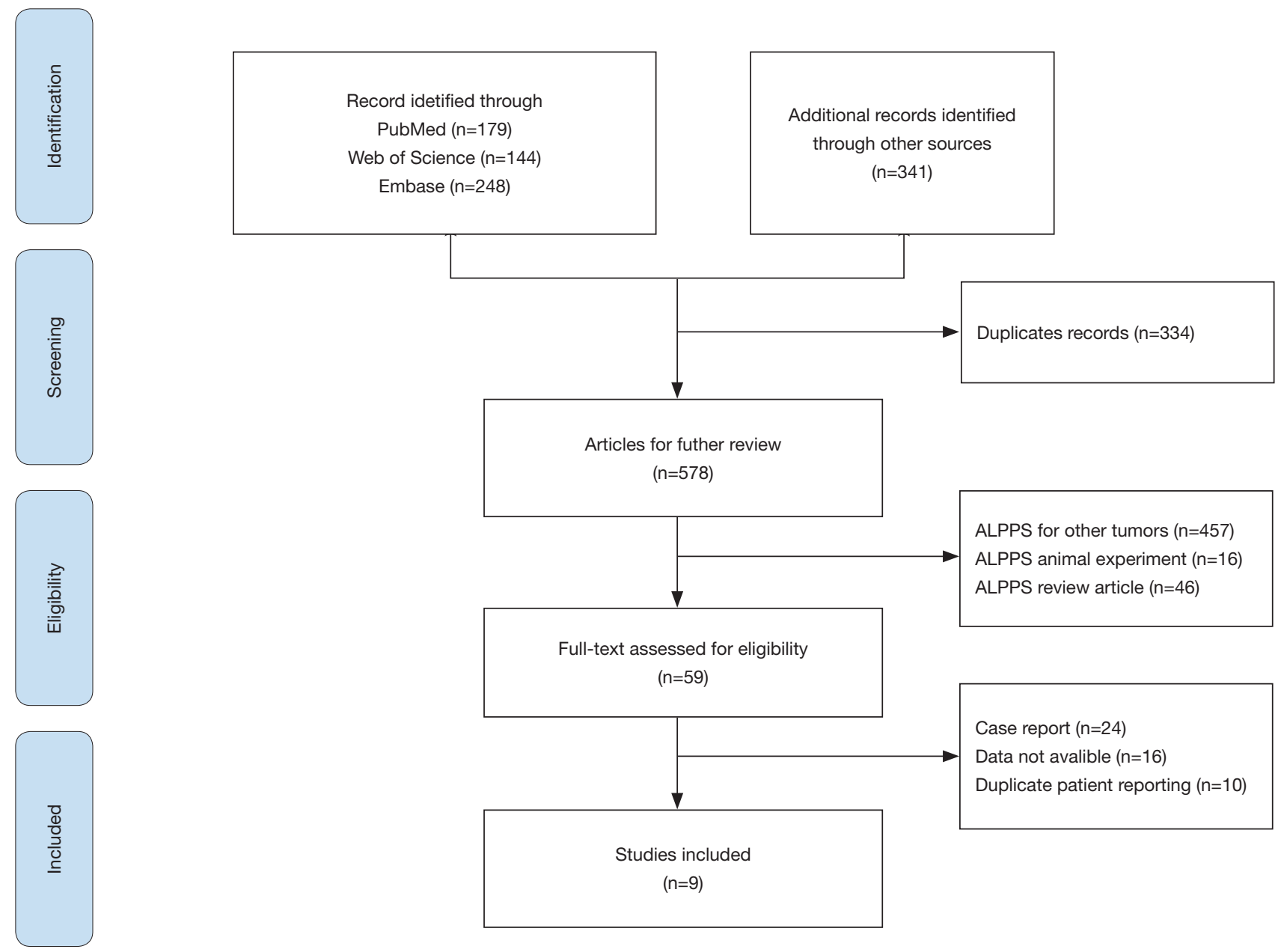

Figure 1 Flow diagram of the study selection process. ALPPS, associating liver partition and portal vein ligation for staged hepatectomy.

Most studies had used the Clavien-Dindo classification standard as the format for reporting complications. Among them, complications above IIIB were considered to be severe, which ranged from $0-25 \%$ after stage 1 and $0-45 \%$ after stage 2. The main topics of all studies focused on the safety of ALPPS in HCC.

\section{Therapeutic effect for ALPPS}

Complete resection (R0) was attained in five studies, and all R0 ratios were 100\% (Table 4). However, the detailed OS and DFS were not reported, except for in three studies (8-10). The first study compared ALPPS with traditional transcatheter arterial chemoembolization (TACE) therapy and one-stage right hepatectomy (RH), which concluded that ALPPS led to markedly superior survival compared with that after TACE, while similar survival was detected following one-stage hepatectomy (8). The second study compared ALPPS with PVE therapy, which showed that ALPPS conferred a higher resection rate in hepatitis-related HCC and had a comparable oncological outcome with PVE (9). The third study compared ALPPS in HCC with CRLM and concluded that HCC patients had the worst survival rate in the initial 90 days, and patient survival was comparable to that for CRLM cases (10). Additionally, one study reported survival in an unconventional way because of small sample size (11).

\section{Discussion}

ALPPS is considered to be a possible solution for managing liver cancer patients without enough FLR, and it has 
Table 1 ALPPS patient characteristics

\begin{tabular}{|c|c|c|c|c|c|c|c|c|c|}
\hline Study & Year & Country & Number & Age & Tumor type & Indication & Surgery & Fibrosis & Evidence \\
\hline Daryl Chia & 2018 & Singapore & 9 & $\begin{array}{l}64.2[54.4- \\
69.8]\end{array}$ & $\begin{array}{l}\text { HCC9, non- } \\
\text { HCC4 }\end{array}$ & $\begin{array}{l}\text { Normal: FLR/TLV <30\%; } \\
\text { cirrhosis: FLR/TLV <40\% }\end{array}$ & ALPPS & Histopathology & $3 b$ \\
\hline $\begin{array}{l}\text { Qiang } \\
\text { Wang }\end{array}$ & 2017 & China & 10 & 41 [33-60] & HCC10 & $\begin{array}{l}\text { Normal: FLR/SLV <30\%; } \\
\text { cirrhosis: FLR/SLV <40\% }\end{array}$ & RALPPS & Metavir grade & 4 \\
\hline Vennarecci & 2016 & Italy & 8 & $61[36-74]$ & $\begin{array}{l}\text { HCC8, } \\
\text { CRLM3, CC2 }\end{array}$ & $\begin{array}{l}\text { Normal: FLR/SLV <30\%, FLR/ } \\
\text { BW <0.5\%; cirrhosis: FLR/SLV } \\
<40 \%, \text { FLR/BW }<0.8 \%\end{array}$ & ALPPS & Metavir grade & $3 b$ \\
\hline D’Haese & 2016 & $\begin{array}{l}\text { Germany } \\
\text { ALPPS } \\
\text { registry }\end{array}$ & 35 & 63 [56-72] & $\begin{array}{l}\text { HCC35, } \\
\text { CRLM225 }\end{array}$ & NA & ALPPS & NA & $2 c$ \\
\hline Björnsso & 2016 & Sweden & 6 & 70.5 [57-83] & HCC6 & FLR/SLV <40\% & ALPPS & NA & 4 \\
\hline
\end{tabular}

ALPPS, associating liver partition and portal vein ligation for staged hepatectomy; HCC, hepatocellular carcinoma; FLR, future liver remnant; SLV, standard liver volume; ICG, indocyanine green angiography; PLT, blood platelet; TLV, total liver volume; CRLM, colorectal liver metastasis; HA, hemangioma; RALPPPS, radiofrequency-assisted ALPPS; ALTPS, tourniquet-assisted ALPPS; NA, not available; CC, cholangiocarcinoma; BW, body weight.

been shown in clinical trials and meta-analyses to achieve favorable hypertrophy for CRLM $(6,7,19)$. ALPPS has been used for about 12 years, but it remains a source of controversy, particularly its treatment for HCC (20).

In terms of feasibility, ALPPS has been shown to improve the resectability relative to that of the conventional twostage liver resection for advanced CRLM patients, although it is performed after preoperative chemotherapy (21). In our study, HCC patients exhibited an average volume increase of $201.8 \mathrm{~mL}$, and the average FLR rate increased from $28.1 \%$ to $73 \%$. The average rate of performing stage II surgery was $96 \%$. Animal experiments have suggested that liver regeneration induced by ALPPS can be achieved in patients with liver fibrosis (22). Currently, the mechanism of liver regeneration for ALPPS remains unclear. Liver regeneration after ALPPS is generally known as a consequence of dramatic portal flow changes and systemic response from parenchymal transection (23).
However, there are still concerns about the feasibility of ALPPS. Most seriously, the increase in liver volume did not correspond to the increased hepatic function. Clinical trials suggest that hepatic function following ALPPS, as evaluated by hepatobiliary scintigraphy, indicates that liver volume overestimates the hepatic function (24). Additionally, histology of the remnant liver shows that the regenerative hepatocytes in ALPPS are morphologically immature relative to those after PVE (25). An experiment in rabbits found that liver parenchymal transection can increase the liver volume rather than hepatic function following the PVE (26). We believe that immature hepatic cells in the early ALPPS stage might account for the high mortality and morbidity that is caused by ALPPS. Therefore, it may be prudent to wait longer before stage 2, but the exact waiting period remains unknown.

In terms of safety, we found a very different 90-day mortality rate from the nine studies that we reviewed. The 


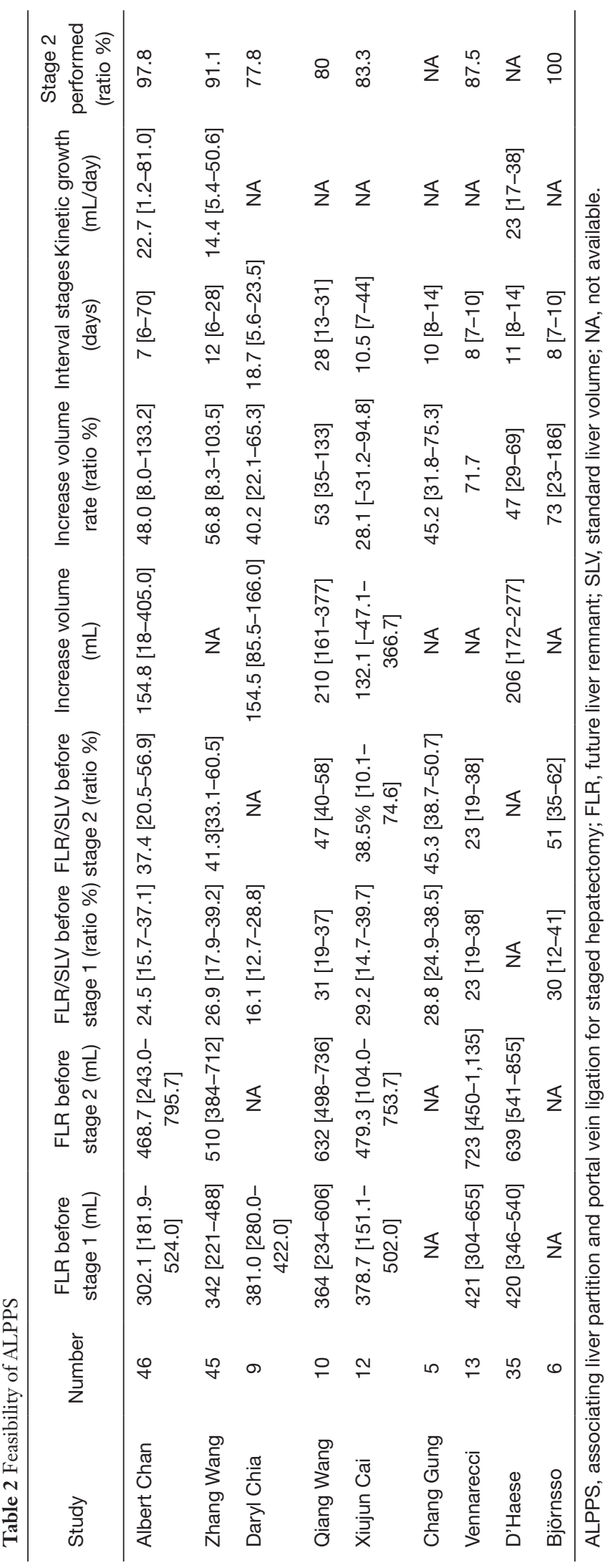


Table 3 Safety of ALPPS

\begin{tabular}{|c|c|c|c|c|c|c|}
\hline Study & $\begin{array}{l}\text { Patients } \\
\text { number }\end{array}$ & $\begin{array}{l}\text { 90-day } \\
\text { mortality } \\
\text { (ratio \%) }\end{array}$ & $\begin{array}{c}\text { Complication rate after } \\
\text { stage } 1 \text { (higher than } \\
\text { grade IIIB) (ratio\%) }\end{array}$ & $\begin{array}{l}\text { Complication rate after } \\
\text { stage } 2 \text { (higher than } \\
\text { grade IIIB) (ratio\%) }\end{array}$ & Main topic & $\begin{array}{l}\text { Main bias based on } \\
\text { study design }\end{array}$ \\
\hline $\begin{array}{l}\text { Zhang } \\
\text { Wang }\end{array}$ & 45 & 11.1 & 8.8 & 14.6 & Safety of ALPPS for HCC & Single experience \\
\hline Qiang Wang & 10 & 40 & 10 & 37.5 & Safety and efficacy of RALPPS & Single experience \\
\hline Xiujun Cai & 12 & 50 & 25 & 45 & $\begin{array}{c}\text { The ALPPS in the treatment of } \\
\text { hepatitis B-related HCC with } \\
\text { cirrhosis }\end{array}$ & Single experience \\
\hline Vennarecci & 13 & 12.5 & 0 & 20 & $\begin{array}{l}\text { ALPPS for primary and secondary } \\
\text { liver tumors }\end{array}$ & Single experience \\
\hline D’Haese & 35 & 31.4 & NA & NA & $\begin{array}{c}\text { Safety of ALPPS for intermediate- } \\
\text { stage HCC }\end{array}$ & $\begin{array}{l}\text { Retrospective } \\
\text { multicenter }\end{array}$ \\
\hline Björnsso & 6 & 0 & 0 & 0 & ALPPS in patients with $\mathrm{HCC}$ & Single experience \\
\hline
\end{tabular}

ALPPS, associating liver partition and portal vein ligation for staged hepatectomy; HCC, hepatocellular carcinoma; PVE, portal vein embolization; NA, not available; RALPPS, radiofrequency-assisted ALPPS.

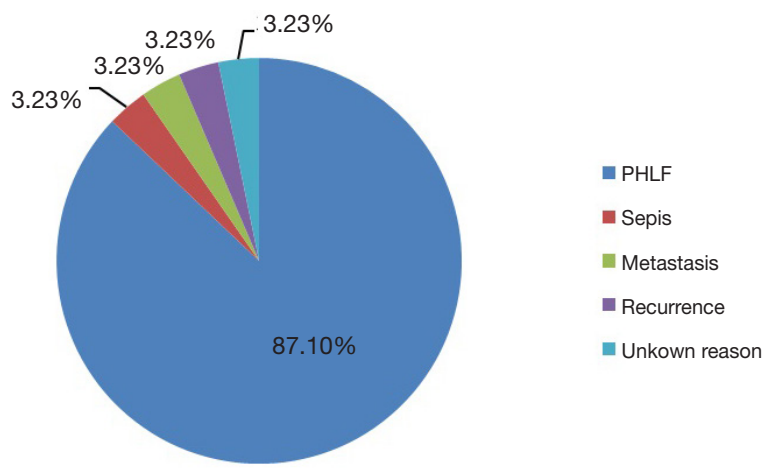

Figure 2 ALPPS mortality rate. ALPPS, associating liver partition and portal vein ligation for staged hepatectomy; PHLF, posthepatectomy liver failure.

90-day mortality ranged from 0-50\%, which showed a large window for improving safety. Post-hepatectomy liver failure accounted for $87.1 \%$ of mortality.

Typically, patient screening, second stage timing, and surgical technique modification are the three ways to potentially avoid hepatic liver failure after surgery. For patient screening, two out of the nine enrolled studies suggested more stringent criteria for screening HCC patients for ALPPS eligibility. Among them, one study suggested that FLR/SLV was too small $(<30 \%)$ and was not recommended for ALPPS in the case of cirrhosis (11). Another study recommended application of ALPPS only in the strictly selected HCC population aged $<60$ years with mild fibrosis (10). Moreover, data in the ALPPS register also showed that the risk score can help to avoid futile ALPPS procedures (27). Therefore, stricter and more specific criteria for ALPPS in HCC patients are necessary to improve its safety. For the timing of stage 2, we suggested that a delayed ALPPS was safer because of the immature hepatocytes, as described above.

To improve surgery, many new surgical procedures have been suggested to make ALPPS safer. Notably, the anterior approach ALPPS in HCC patients has been well investigated, and has been shown to avoid severe adhesion formation, and improve the safety of ALPPS $(9,28)$. There 
Table 4 Oncologic efficacy of ALPPS

\begin{tabular}{|c|c|c|c|c|c|c|c|c|}
\hline Study & $\begin{array}{l}\text { Number of R0 } \\
\text { resections (\%) }\end{array}$ & $\begin{array}{l}\text { OS at } 1 \\
\text { year }(\%)\end{array}$ & $\begin{array}{l}\text { OS at } 3 \\
\text { years }(\%)\end{array}$ & $\begin{array}{l}\text { Median survival, } \\
\text { (months) }\end{array}$ & $\begin{array}{l}\text { DFS at } 1 \\
\text { year }(\%)\end{array}$ & $\begin{array}{l}\text { DFS at } 3 \\
\text { years (\%) }\end{array}$ & $\begin{array}{c}\text { Median DFS } \\
\text { (months) }\end{array}$ & $\begin{array}{l}\text { Critical oncological discussion } \\
\text { points by authors }\end{array}$ \\
\hline $\begin{array}{l}\text { Albert } \\
\text { Chan }\end{array}$ & 100 & 84.7 & 60.2 & NA & 63.2 & 34.9 & NA & $\begin{array}{l}\text { ALPPS same as PVE but higher } \\
\text { resection rate }\end{array}$ \\
\hline $\begin{array}{l}\text { Zhang } \\
\text { Wang }\end{array}$ & 100 & 64.2 & 60.2 & NA & 47.6 & 43.6 & NA & $\begin{array}{l}\text { ALPPS same as one stage } \mathrm{RH} \text {, } \\
\text { better than TACE }\end{array}$ \\
\hline $\begin{array}{l}\text { Qiang } \\
\text { Wang }\end{array}$ & 100 & NA & NA & NA & NA & NA & NA & $\begin{array}{l}\text { RALPPS is at the cost of a longer } \\
\text { interval time }\end{array}$ \\
\hline Xiujun Cai & 100 & 50 & 28.6 & NA & NA & NA & NA & $\begin{array}{c}\text { FLR/SLV }<30 \% \text { is not recommended } \\
\text { for ALPPS in HCC }\end{array}$ \\
\hline Vennarecci & 100 & NA & NA & NA & NA & NA & $\mathrm{Na}$ & $\begin{array}{c}\text { ALPPS induced FLR growth in HCC } \\
\text { same as non-HCC }\end{array}$ \\
\hline D’Haese & NA & NA & NA & NA & NA & NA & 12 & $\begin{array}{l}\text { ALPPS for HCC should be } \\
\text { performed only for younger than } \\
60 \text { years with low-grade fibrosis }\end{array}$ \\
\hline Björnsso & NA & NA & NA & NA & NA & NA & NA & $\begin{array}{l}\text { ALPPS may be applied in selected } \\
\text { patients with HCC }\end{array}$ \\
\hline
\end{tabular}

ALPPS, associating liver partition and portal vein ligation for staged hepatectomy; OS, overall survival; DFS, disease-free survival; NA, not available; PVE, portal vein embolization; $\mathrm{RH}$, right hepatectomy; TACE, transcatheter arterial chemoembolization; HCC, hepatocellular carcinoma; RALPPS, radiofrequency-assisted ALPPS; FLR, future liver remnant; SLV, standard liver volume.

is a case report that used transhepatic arterial embolization (TAE) following the failure of stage-I ALPPS for an advanced HCC case, which is based on the theory that advanced HCC can rob the FLR of arterial blood flow, resulting in slow and restricted FLR hypertrophy (29). There are also case reports about the successful implementation of laparoscopic ALPPS for HCC only (30). For liver resection, recent research suggests that a difference in partial in situ splits among CRLM or nonHCC patients is not statistically significant compared with that of complete in situ splits; however, there are no data for HCC (31). To minimize the damage from the first step, a "mini-ALPPS" is performed, which integrates transection of the parenchyma with intraoperative PVE, and promotes superior recovery of patients before stage II (32).

Data on long-term survival in HCC patients after ALPPS are lacking. Only three studies systematically investigated the OS and DFS, which suggested that ALPPS was better than traditional TACE therapy, that it was comparable to PVE but had a higher resection rate, and that it was as effective as one-stage liver resection. The results from these studies show that ALPPS has potential merit as an option that is suitable for HCC patients.

A major strength of this study was that it was the first study to systematically review the safety, feasibility, and therapeutic effect of ALPPS on HCC patients. Second, it included data from many centers across the world, which made it more convincing. Third, this study included a quantitative analysis, which might lead to more convincing outcomes.

However, there are certain limitations. First, retrospective studies are more likely to have potential biases. Second, single-center studies on HBV-related patients were under-represented because publication bias might have strongly affected their results. Third, the limited data on long-term survival reduced the persuasiveness of this study.

Additional data on HCC patients are required to further refine indications and to show the efficacy of ALPPS 
for HCC patients. To further validate the advantages of ALPPS, well-designed and multi-center randomized controlled trials are needed. Additionally, ALPPS status should be established on the basis of long-term oncological outcomes, which can serve as a treatment for HCC patients. ALPPS, as a novel surgical procedure, should be further investigated regarding its feasibility, safety, and efficacy for HCC patients. ALPPS is a therapeutic procedure for HCC, but it is a double-edged sword that must be used correctly. Moreover, attention should be placed on important measures that will improve patient selection, identify the timing of the second stage, and modify the surgical techniques that are used in ALPPS.

\section{Conclusions}

In conclusion, ALPPS is safe and feasible in the treatment of selected patients with unresectable HCC. However, its oncological outcome should be shown in more studies such as well-designed clinical trials. Notably, RALPPS is not recommended for HCC patients because RALPPS requires patients to wait for a long time between stages.

\section{Acknowledgments}

We acknowledge that anyone who makes contributions to this article is included in the study. All authors have permitted the publication of this article. We thank Jodi Smith, PhD, from Liwen Bianji, Edanz Editing China (www. liwenbianji.cn/ac), for editing the English text of a draft of this manuscript.

Funding: This article had been funded from the International Science and Technology Cooperation Projects (2016YFE0107100), the Capital Special Research Project for Health Development (2014-2-4012), the Beijing Natural Science Foundation (L172055), the Fundamental Research Funds for the Central Universities (3332018032), and the CAMS Innovation Fund for Medical Science (CIFMS) (2017-I2M-4-003 and 2018-I2M-3-001).

\section{Footnote}

Reporting Checklist: The authors have completed the PRISMA reporting checklist. Available at http://dx.doi.org/10.21037/ atm-20-2214

Peer Review File: Available at http://dx.doi.org/10.21037/ atm-20-2214
Conflicts of Interest: All authors have completed the ICMJE uniform disclosure form (available at http://dx.doi. org/10.21037/atm-20-2214). The authors have no conflicts of interest to declare.

Ethical Statement: The authors are accountable for all aspects of the work in ensuring that questions related to the accuracy or integrity of any part of the work are appropriately investigated and resolved. Ethical approval is not needed in this study due to its review nature. There is no need to get individual consent since it is a review article.

Open Access Statement: This is an Open Access article distributed in accordance with the Creative Commons Attribution-NonCommercial-NoDerivs 4.0 International License (CC BY-NC-ND 4.0), which permits the noncommercial replication and distribution of the article with the strict proviso that no changes or edits are made and the original work is properly cited (including links to both the formal publication through the relevant DOI and the license). See: https://creativecommons.org/licenses/by-nc-nd/4.0/.

\section{References}

1. Bray F, Ferlay J, Soerjomataram I, et al. Global cancer statistics 2018: GLOBOCAN estimates of incidence and mortality worldwide for 36 cancers in 185 countries. CA Cancer J Clin 2018;68:394-424.

2. Liu CY, Chen KF, Chen PJ, et al. Treatment of liver cancer. Cold Spring Harb Perspect Med 2015;5:a021535.

3. Agrawal S, Belghiti J. Oncologic resection for malignant tumors of the liver. Ann Surg 2011;253:656-65.

4. Schnitzbauer AA, Lang SA, Goessmann H, et al. Right portal vein ligation combined with in situ splitting induces rapid left lateral liver lobe hypertrophy enabling 2 -staged extended right hepatic resection in small-for-size settings. Ann Surg 2012;255:405-14.

5. Olthof PB, Schnitzbauer AA, Schadde E. The HPB controversy of the decade: 2007-2017 - Ten years of ALPPS. Eur J Surg Oncol 2018;44:1624-7.

6. Sandström P, Røsok BI, Sparrelid E, et al. ALPPS improves resectability compared with conventional twostage hepatectomy in patients with advanced colorectal liver metastasis: results from a Scandinavian multicenter randomized controlled trial (LIGRO trial). Ann Surg 2018;267:833-40.

7. Moris D, Ronnekleiv-Kelly S, Kostakis ID, et al. Operative results and oncologic outcomes of associating liver 
partition and portal vein ligation for staged hepatectomy (ALPPS) versus two-stage hepatectomy (TSH) in patients with unresectable colorectal liver metastases: a systematic review and meta-analysis. World J Surg 2018;42:806-15.

8. Wang Z, Peng Y, Hu J, et al. Associating liver partition and portal vein ligation for staged hepatectomy for unresectable hepatitis B virus-related hepatocellular carcinoma. Ann Surg 2020;271:534-41.

9. Chan A, Zhang WY, Chok K, et al. ALPPS versus portal vein embolization for hepatitis-related hepatocellular carcinoma: a changing paradigm in modulation of future liver remnant before major hepatectomy. Ann Surg 2019. [Epub ahead of print].

10. D'Haese JG, Neumann J, Weniger M, et al. Should ALPPS be used for liver resection in intermediate-stage HCC? Ann Surg Oncol 2016;23:1335-43.

11. Cai X, Tong Y, Yu H, et al. The ALPPS in the treatment of hepatitis B-related hepatocellular carcinoma with cirrhosis: a single-center study and literature review. Surg Innov 2017;24:358-64.

12. Wang Q, Yan J, Feng X, et al. Safety and efficacy of radiofrequency-assisted ALPPS (RALPPS) in patients with cirrhosis-related hepatocellular carcinoma. Int J Hyperthermia 2017;33:846-52.

13. Wigmore SJ. ALPPS: The argument against. Eur J Surg Oncol 2017;43:249-51.

14. Schadde E, Schnitzbauer AA, Tschuor C, et al. Systematic review and meta-analysis of feasibility, safety, and efficacy of a novel procedure: associating liver partition and portal vein ligation for staged hepatectomy. Ann Surg Oncol 2015;22:3109-20.

15. Björnsson B, Røsok B,Sparrelid E, et al. ALPPS in patients with HCC. HPB 2016;18:e205.

16. Wang CC, Komorowski AL, Chen CL, et al. Associating liver partition with portal vein ligation for staged hepatectomy (ALPPS) for hepatocellular cancer treatment. Is it safe? Eur J Surg Oncol 2016;42:S164.

17. Chia DKA, Yeo Z, Loh SEK, et al. ALPPS for hepatocellular carcinoma is associated with decreased liver remnant growth. J Gastrointest Surg 2018;22:973-80.

18. Vennarecci G, Grazi GL, Sperduti I, et al. ALPPS for primary and secondary liver tumors. Int J Surg 2016;30:38-44.

19. Hasselgren K, Rosok BI, Larsen PN, et al. ALPPS improves survival compared with TSH in patients affected of CRLM: survival analysis from the randomized controlled trial LIGRO. Ann Surg 2019. [Epub ahead of print].

20. Lau WY. Associating liver partition and portal vein ligation for staged hepatectomy (ALPPS) and its further developments in the last decade. Hepatobiliary Surg Nutr 2019;8:258-9.

21. Vondran FWR, Oldhafer F, Ringe KI, et al. Associating liver partition and portal vein ligation for staged hepatectomy after pre-operative chemotherapy. ANZ J Surg 2018;88:E324-8.

22. Yifan T, Ming X, Yifan $W$, et al. Hepatic regeneration by associating liver partition and portal vein ligation for staged hepatectomy (ALPPS) is feasible but attenuated in rat liver with thioacetamide-induced fibrosis. Surgery 2019;165:345-52.

23. Moris D, Vernadakis S, Papalampros A, et al. Mechanistic insights of rapid liver regeneration after associating liver partition and portal vein ligation for stage hepatectomy. World J Gastroenterol 2016;22:7613-24.

24. Olthof PB, Tomassini F, Huespe PE, et al. Hepatobiliary scintigraphy to evaluate liver function in associating liver partition and portal vein ligation for staged hepatectomy: liver volume overestimates liver function. Surgery 2017;162:775-83.

25. Matsuo K, Murakami T, Kawaguchi D, et al. Histologic features after surgery associating liver partition and portal vein ligation for staged hepatectomy versus those after hepatectomy with portal vein embolization. Surgery 2016;159:1289-98.

26. Olthof PB, Schadde E, van Lienden KP, et al. Hepatic parenchymal transection increases liver volume but not function after portal vein embolization in rabbits. Surgery 2017;162:732-41.

27. Linecker M, Stavrou GA, Oldhafer KJ, et al. The ALPPS risk score: avoiding futile use of ALPPS. Ann Surg 2016;264:763-71.

28. Chan AC, Poon RT, Lo CM. Modified anterior approach for the ALPPS procedure: how we do it. World J Surg 2015;39:2831-5.

29. Wang Z, Peng Y, Sun Q, et al. Salvage transhepatic arterial embolization after failed stage I ALPPS in a patient with a huge HCC with chronic liver disease: a case report. Int J Surg Case Rep 2017;39:131-5.

30. Rong Z, Lu Q, Yan J. Totally laparoscopic radiofrequencyassisted liver partition with portal vein ligation for hepatocellular carcinoma in cirrhotic liver. Medicine 2017;96:e9432.

31. Petrowsky H, Gyori G, de Oliveira M, et al. Is partial- 
ALPPS safer than ALPPS? A single-center experience. Ann Surg 2015;261:e90-2.

32. de Santibañes E, Alvarez FA, Ardiles V, et al. Inverting the ALPPS paradigm by minimizing first stage impact: the Mini-ALPPS technique. Langenbecks Arch Surg 2016;401:557-63.

Cite this article as: Zhang J, Huang H, Bian J, Sang X, Xu Y, Lu X, Zhao H. Safety, feasibility, and efficacy of associating liver partition and portal vein ligation for staged hepatectomy in treating hepatocellular carcinoma: a systematic review. Ann Transl Med 2020;8(19):1246. doi: 10.21037/atm-20-2214 